\title{
BMJ Open Care seeking in tuberculosis: results from a countrywide cluster randomised survey in Bangladesh
}

\author{
Shahed Hossain, ${ }^{1} \mathrm{~K}$ Zaman, ${ }^{1}$ Abdul Quaiyum, ${ }^{1}$ Sayera Banu, ${ }^{1}$ Ashaque Husain, ${ }^{2}$ \\ Akramul Islam, ${ }^{3}$ Martien Borgdorff, ${ }^{4,5,6}$ Frank van Leth ${ }^{7,8}$
}

To cite: Hossain S, Zaman K, Quaiyum A, et al. Care seeking in tuberculosis: results from a countrywide cluster randomised survey in Bangladesh. BMJ Open 2014;4:e004766.

doi:10.1136/bmjopen-2013004766

- Prepublication history for this paper is available online. To view these files please visit the journal online (http://dx.doi.org/10.1136/ bmjopen-2013-004766).

Received 28 December 2013 Revised 22 April 2014 Accepted 28 April 2014

CrossMark

For numbered affiliations see end of article.

Correspondence to Dr Shahed Hossain; shahed@icddrb.org

\section{ABSTRACT}

Objectives: To explore systematically the care seeking trajectories of tuberculosis (TB) cases up to four subsequent places of care and to assess the type of services provided at each place.

Methods: TB cases detected actively during the 2007-2009 national TB prevalence survey and passively under the routine programme in the same period were interviewed by administering a standardised questionnaire. Care seeking and services provided up to four subsequent points were explored. Care seeking was further explored by categorising the providers into formal, informal and 'self-care' groups.

Results: A total of 273 TB cases were included in this study, of which $33(12 \%)$ were detected during the survey and $240(88 \%)$ from the TB registers. Out of the 118 passively detected cases who first sought care from an informal provider, $52(44.1 \%)$ remained in the informal sector at the second point of care. Similarly, out of the $52,17(32.7 \%)$ and out of the 17, 5

$(29.4 \%)$ remained in the informal sector at the third and fourth subsequent points of care, respectively. All the 33 actively detected cases had 'self-care' at the first point, and $27(81.8 \%)$ remained with 'self-care' up to the fourth point of care. Prescribing drugs (59-99\%) was the major type of care provided by the formal and informal care providers at each point and was limited to the non-existent practice of investigation or referrals. Conclusions: Free TB services are still underutilised by TB cases and informal caregivers remained the major care providers for such cases in Bangladesh. In order to improve case detection, it is necessary that the National Tuberculosis Programme immediately takes effective initiatives to engage all types of care providers, particularly informal providers who are the first point of care for the majority of the TB suspects.

\section{INTRODUCTION}

Bangladesh has successfully implemented directly observed treatment, short-course (DOTS), the WHO advocated tuberculosis (TB) control strategy since 1993. Since then, impressive case detection and cure rates were recorded under DOTS. However, from 2006

\section{Strengths and limitations of this study}

- Included actively and passively detected tuberculosis cases from all over the country and explored a wide spectrum of care seeking.

- Covered care seeking up to four subsequent points of care.

- Clusters were selected from the rural or urban areas equally, which might not reflect the underlying population distribution of the country.

onwards, case notification became stagnant and even started to show a declining trend. ${ }^{1}{ }^{2}$ It is likely that a substantial number of cases are not notified under the National Tuberculosis Programme (NTP), and are probably getting treatment from the private sector or not receiving care at all. ${ }^{3-5}$

The current TB control strategy is based, among others, on passive case detection, which is influenced by many heath system and patient factors. A patient's knowledge on TB symptoms, their presence and severity influence on the intention of care seeking. ${ }^{6}{ }^{7}$ Similarly, availability and access to anti-TB services, and providers' behaviour also influence care seeking practices and outcomes. ${ }^{8} 9$ Care seeking, therefore, is an important determinant that influences not only the individual's disease status and its prognosis, but also reflects on the epidemiology of TB in a community.

Caregivers play a crucial role in the care seeking pathway of individuals with symptoms of tuberculosis. In Bangladesh, healthcare services are provided by formal and informal providers. Within the organisation of TB control in Bangladesh, formal providers are licensed medical practitioners (public or private) who graduated from a medical college, or health workers (public or through non-governmental organisations) approved by the NTP, who received training to suspect, examine and refer TB cases to initiate TB treatment at DOTS centres. 
Informal providers are non-qualified private practitioners who are not licensed or did not receive any formal training (eg, village doctors, paramedics and pharmacy persons). ${ }^{10} 11$ However, the NTP acknowledges the important role of private sector providers, including informal providers, and urged involve them to achieve TB control objectives through a systematic public-private mix approach.

Informal providers comprise $95 \%$ of the total health workers of Bangladesh. They are frequently the point of first care for $\mathrm{TB}$ and other chronic conditions due to many conditions including ease of access to their services. ${ }^{4}{ }^{12-15}$ However, case management within the informal sector remains unpredictable, and outcomes are hardly ever known. ${ }^{13} 1617$

With freely available DOTS services throughout the country, it was expected that all persons irrespective of socioeconomic status would access and utilise this service. However, recent findings of the national TB prevalence survey 2007-2009 of Bangladesh revealed that only $9 \%$ of actively identified TB cases were known to the NTP, ${ }^{18}$ indicating that the others were remaining in the community either without treatment or getting treatment from elsewhere. The same survey showed that care utilisation from DOTS centres was mostly from higher socioeconomic position (SEP), while prevalent TB cases were mainly seen on the lower SEP strata. SEP was assessed by validated asset items for households and the actively identified cases from survey were compared with passively detected cases under NTP over the identical SEP quartiles. Among the actively detected cases, $75.8 \%$ were from the lower two quartiles, while among the passive TB cases more than half, $57.1 \%$, were from the uppermost two quartiles, $40.8 \%$ from the second quartile and $2.1 \%$ from the lowest quartile of the population. This distribution did not change after adjustments for other factors or interactions among them. ${ }^{5} 18$ These findings indicate that availability of a service does not ensure its utilisation, as has also been observed in other sectors. ${ }^{8}$

With inadequate, or absence of, initial care of TB cases fuelling further transmission of the disease in the general population, it is important to understand the care seeking pathway of the persons with TB symptoms with respect to where care is initiated, and what action is taken by the care provider at the presentation of an individual with chronic cough (as a strong marker for possible TB). The course of the disease is probably much determined at the point of first contact and in the subsequent points.

In this study, we interviewed TB cases detected actively in a national TB prevalence survey, and cases detected passively under routine programme conditions. The objective was to explore their care seeking behaviour up to four subsequent points of taking care. The study will identify areas to target by NTP for improved implementation of its activities to increase case finding and appropriate care.

\section{METHODS AND MATERIALS}

\section{Setting and study population}

The study was embedded within the national TB prevalence survey that Bangladesh carried out throughout the country during 2007-2009. This was a cross-sectional survey which included 40 randomly selected clusters. ${ }^{18}$ Subdistricts were the primary sampling units which were selected proportional to population size. Nearly 52000 adults ( $\geq 15$ years) were included for sputum examination and 33 new smear positive TB cases were identified. For this analysis, we interviewed all these 33 actively detected cases and included 6 controls per cluster. The controls were the most recent passively detected cases under treatment from the TB registers of each of the 40 clusters' DOTS centres. All the cases were new smear positive pulmonary TB cases, and were diagnosed by direct sputum smear microscopy as per NTP guidelines. The detail of methodology is described elsewhere. ${ }^{18}$

\section{Data collection}

Data were collected by interviewing all detected survey cases at their households. A standard questionnaire was administered by trained survey coordinators immediately after the diagnosis of a case in the survey. The initial questionnaire was translated into Bangla, pretested and revised to incorporate review comments from users and experts. The survey coordinators received 1 week's training at the Dhaka project office. The training included a thorough understanding of the components of the questionnaire and interview techniques to obtain reliable answers. The particulars of the 240 NTP cases were obtained from the TB register at the cluster-specific DOTS centre, after which the persons were visited at their home for an interview. Informed written consent was taken from all participants. All completed questionnaires were checked for completeness and appropriateness by a supervisor, who also reinterviewed a number of cases from randomly selected clusters for cross checking.

\section{Measurements}

The interviews provided information on the demographics and symptom profile of the cases, SEP, care utilisation pattern and services received at each point of care visited. The demographic data included age, sex, place of residence, levels of education and occupation. SEP was assessed by asset estimation. ${ }^{19}$ The symptom profile recorded the symptoms presented at first care seeking. The care seeking data provided information on where care was sought, in what order and what measures were taken by the providers at each point. The detail of socioeconomic data collection is described elsewhere. ${ }^{5}$

\section{Statistical approach}

Data were analysed using the statistical package Stata 12.0 (Stata Corp., USA). The initial general description provides the characteristics of the study population. Age, education, occupation and symptom variables were presented in natural subgroups. Asset estimation was based 
on a set of assets that the household possessed and a weight was allocated to each asset generated through a principal component analysis. ${ }^{20}$ We included items and methods as standardised and followed by the Bangladesh Demographic and Health Survey 2001. ${ }^{20} 21$ The SEP of the study population was divided into quartiles. Care seeking from the first to fourth subsequent points was explored. The types of providers were categorised as formal or informal as described earlier. We added a group as 'self-care' to denote the use of any treatment obtained outside the formal or informal health sector (eg, home remedies, self-medication).

Measures taken at each point of care seeking were grouped in four categories. These were only words of advice offered, investigations ordered and medications given or referred for further investigations. The care seeking and actions taken were reported by the patients at the interview. We did not verify them either by checking the prescription or by any other methods. We focused our analysis on the care seeking patterns of those cases who initiated their care seeking trajectory at the informal care sector.

\section{RESULTS}

A total of $273 \mathrm{~TB}$ cases were included in this study, of which $33(12 \%)$ were detected during the survey and $240(88.0 \%)$ from the TB registers. Among the participants, $120(43.9 \%)$ were under 34 years of age, and 176 $(64.5 \%)$ were men. Participants were almost equally from rural and urban areas. More than $50 \%$ of the cases presented with more than five symptoms. Most of the participants had cough, including $81.3 \%$ for 15 days or more (table 1). Among those, the mean delay from onset of symptoms to seek any care from any provider was 31 days, which was 20 days for survey cases and 33 days for the NTP cases under NTP (not shown).

Table 1 Sociodemographic characteristics of the actively detected survey cases and passively detected NTP cases

\begin{tabular}{|c|c|c|c|c|c|c|c|}
\hline Characteristics & $\begin{array}{l}\text { All } \\
N(273)\end{array}$ & Per cent & $\begin{array}{l}\text { Survey cases } \\
\mathrm{n}(33)\end{array}$ & Per cent & $\begin{array}{l}\text { NTP cases } \\
\mathrm{n}(240)\end{array}$ & Per cent & p Value \\
\hline \multicolumn{8}{|l|}{ Age in years } \\
\hline $15-34$ & 120 & 43.9 & 8 & 24.2 & 112 & 46.6 & 0.028 \\
\hline $35-54$ & 87 & 31.9 & 12 & 36.6 & 75 & 31.2 & \\
\hline $55+$ & 66 & 25.0 & 13 & 39.9 & 53 & 22.1 & \\
\hline \multicolumn{8}{|l|}{ Sex } \\
\hline Male & 176 & 64.5 & 24 & 72.7 & 152 & 63.3 & 0.290 \\
\hline Female & 97 & 35.5 & 9 & 27.7 & 88 & 36.7 & \\
\hline \multicolumn{8}{|l|}{ Residence } \\
\hline Rural & 140 & 51.3 & 20 & 60.6 & 120 & 50.0 & 0.253 \\
\hline Urban & 133 & 48.7 & 13 & 39.4 & 120 & 50.0 & \\
\hline \multicolumn{8}{|l|}{ Education } \\
\hline 0 & 71 & 26.0 & 15 & 45.5 & 55 & 23.0 & 0.039 \\
\hline $1-5$ & 71 & 26.0 & 8 & 24.2 & 65 & 27.1 & \\
\hline $6-10$ & 68 & 24.9 & 6 & 18.2 & 62 & 25.8 & \\
\hline $10+$ & 63 & 23.1 & 4 & 12.1 & 58 & 24.2 & \\
\hline \multicolumn{8}{|l|}{ Occupation } \\
\hline Agriculture based & 37 & 13.6 & 4 & 12.1 & 33 & 13.8 & 0.003 \\
\hline Daily wagers & 89 & 22.3 & 14 & 42.4 & 75 & 31.3 & \\
\hline Sales and services & 115 & 28.2 & 6 & 18.2 & 109 & 45.4 & \\
\hline Others & 32 & 35.9 & 9 & 27.3 & 23 & 9.6 & \\
\hline \multicolumn{8}{|l|}{ Asset quartiles } \\
\hline 1st (lowest) & 17 & 6.2 & 12 & 36.4 & 5 & 2.0 & 0.000 \\
\hline 2nd & 111 & 40.6 & 13 & 39.4 & 98 & 41.0 & \\
\hline $3 r d$ & 113 & 41.4 & 5 & 15.1 & 108 & 45.0 & \\
\hline 4th & 32 & 11.8 & 3 & 9.1 & 29 & 12.0 & \\
\hline \multicolumn{8}{|l|}{ Presence of cough } \\
\hline Yes & 226 & 82.8 & 29 & 87.8 & 197 & 82.1 & 0.408 \\
\hline No & 47 & 17.2 & 4 & 12.2 & 43 & 17.9 & \\
\hline \multicolumn{8}{|l|}{ Duration of cough } \\
\hline Less than 14 days & 51 & 18.7 & 6 & 18.2 & 45 & 18.2 & 0.937 \\
\hline$\geq 15$ days & 222 & 81.3 & 27 & 81.8 & 195 & 81.8 & \\
\hline \multicolumn{8}{|l|}{ Number of symptoms } \\
\hline$\leq 2$ & 44 & 16.1 & 4 & 12.1 & 40 & 16.7 & 0.556 \\
\hline $3-4$ & 79 & 29.0 & 8 & 24.2 & 71 & 29.6 & \\
\hline $5+$ & 150 & 54.9 & 21 & 63.7 & 129 & 53.8 & \\
\hline
\end{tabular}


Among the 240 cases detected passively under NTP, $118(49.1 \%)$ sought initial care from informal providers, $106(44.2 \%)$ from formal providers and $16(6.7 \%)$ used self-care. All of the 33 actively detected cases had initial 'self care' and together with the 16 passively detected cases, the proportion of 'self care' at the first point of care was $49(17.9 \%)$ among all cases (figure 1). Out of the 118 passively detected NTP cases with initial care from the informal sector, $52(44.1 \%)$ remained in the informal sector, while $61(51.7 \%)$ switched to a formal provider for care at the second point care. Again, among the 52 who remained in the informal care sector, at the third point of care $32(61.5 \%)$ migrated to the formal care sector, while $17(32.7 \%)$ remained in the informal sector. The proportion of patients who remained in the informal care sector up to the fourth point care was five $(29.4 \%)$ of those stating their health seeking behaviour in the informal sector (figure 1). Among the 16 (6.7\%) NTP cases who reported self-care as their initial strategy, ultimately four $(25.0 \%)$ remained in this stage up to the fourth point of care, three $(18.8 \%)$ moved to the informal sector and nine $(56.2 \%)$ subsequently migrated to the formal care sector. Among the active detected cases, all of whom had self-care as the initial strategy, $27(81.8 \%)$ remained at this stage before being detected by the survey. Among the remaining six, three shifted to the formal sector at the second point of care, while the other three switched between informal and formal providers in the subsequent points of care (not shown).

We looked into the measures taken at each point of care by the formal and informal providers. In the formal care sector, the primary action was to prescribe drugs at each point of care starting with $79(74.5 \%)$ at the first point, $43(70.5 \%)$ at the second point, $19(59.4 \%)$ at the third point and $10(91 \%)$ at the fourth point of care. Ordering diagnostic investigations varied from 19

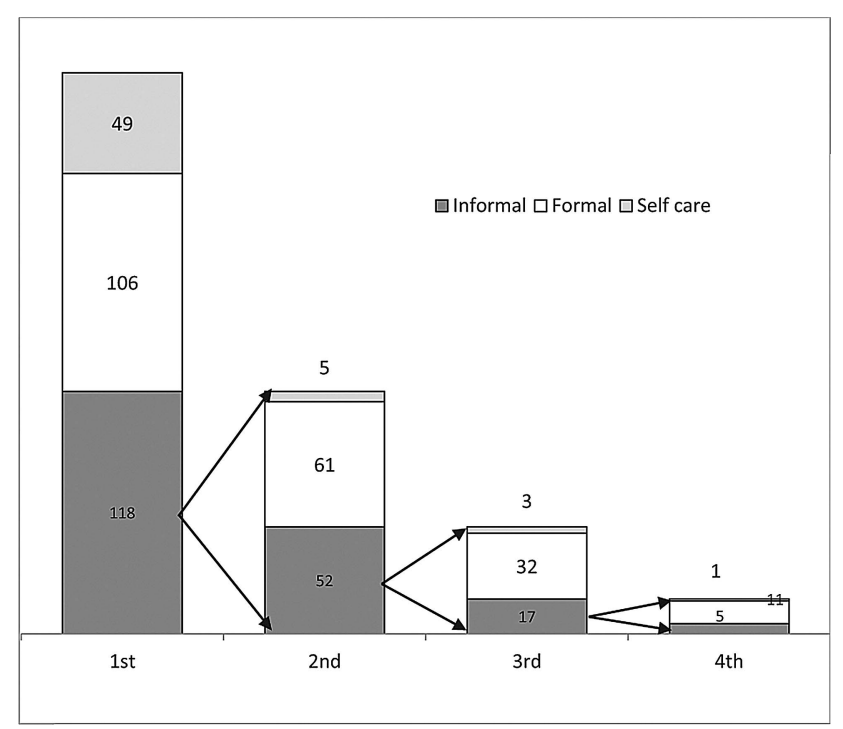

Figure 1 Care seeking at different points of care.
$(17.9 \%)$ at the first point of care, to $14(22.9 \%)$ at the second, $10(31.2 \%)$ at the third and $1(9 \%)$ at the fourth point of care. Referral for further investigation was seldom done $(0-2 \%)$. The informal providers, on the other hand, prescribed drugs in $80-99 \%$ of the encounters, and seldom ordered diagnostic investigations or referred the individual for further investigations at any of the four points of care (figure 2).

The reasons for not seeking care at all were available only from the 33 survey cases. The major reasons were not considering symptoms serious enough, and monetary constraints.

\section{DISCUSSION}

Our study showed that most of the initial care seeking by passively identified TB cases happened at the informal sector or was limited to self-care. At each following round of care seeking, a third to a half remained in the informal care sector. Among the actively detected cases, more than $80 \%$ remained in the self-care sector up to the time of their identification by the survey. Case management in the informal sector was restricted to prescribing any medications, with non-existence of any diagnostic investigations or referrals.

Preference for informal providers as an initial place of care has been reported from Bangladesh and elsewhere. ${ }^{3-5} 9{ }^{12}$ In chronic conditions where symptom onset is slow and insidious like tuberculosis, people usually consult with an informal provider available at hand or consume over the counter drugs. This behaviour can cause a marked delay in starting appropriate TB medication, given the fact that TB medication in line with the NTP guideline is seldom present in the informal health sector. This has been observed in earlier studies from Bangladesh. ${ }^{4}$ Our study adds the important finding that this preference of the informal sector persists throughout the care seeking trajectory. The lack of (referral for) diagnostic investigation can cause additional systems delay (between care seeking and starting appropriate treatment). An earlier study reported that this type of delay could be more than 10 weeks. ${ }^{4}$ Delay to reach appropriate care and treatment impacts on the course of the disease and may result in unfavourable outcomes and ongoing transmission. ${ }^{22}$ From a programmatic point of view, this situation leads to a marked under reporting of TB cases.

Care seeking from the informal sector is not limited to $\mathrm{TB}$ only, but is rather a common feature for all chronic conditions in Bangladesh. ${ }^{15} 23$ It is suggested that the presence of huge numbers of informal providers in rural and urban areas, their easy accessibility due to reduced cost and minimal levels of stigma when attending such providers encourage people to seek care from this sector first. ${ }^{1523} 24$ A good portion of them are simple drug sellers providing drugs without further diagnostic procedures. ${ }^{12}$ This easy access to informal providers stimulates 'shopping for care', when care is sought 

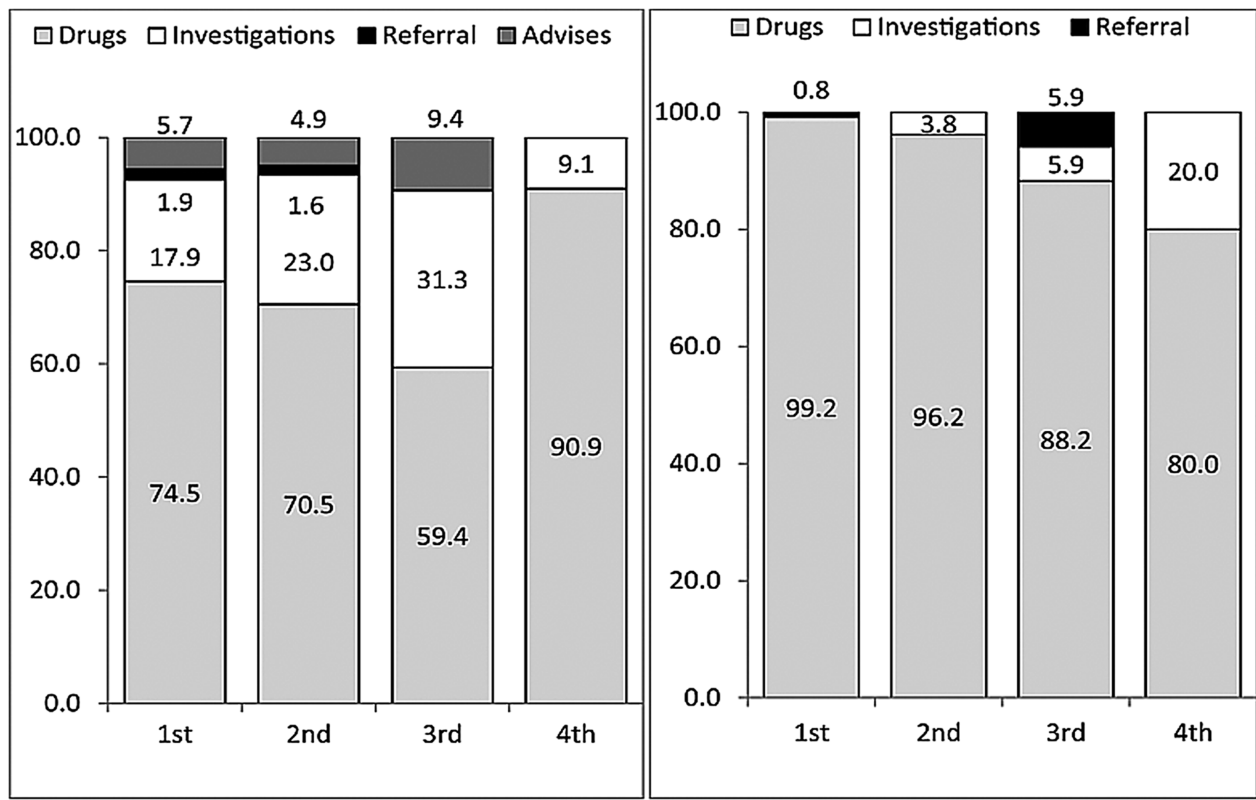

Formal providers

Informal providers

Figure 2 Actions taken if care sought from formal and informal providers.

from informal providers subsequently one after one, as observed in our study. In Malawi, care seeking among patients with TB noted that multiple contacts in the range of 1-15 were made before the diagnosis. ${ }^{25}$ Similarly, in Vietnam, patients made on average 1.3 contacts and 2.5 visits per provider before getting appropriate TB services, even though the size of private sector was very small. ${ }^{26}$

We observed that the case management was not altogether different in the formal and informal sectors with respect to prescribing drugs. However, unlike in the formal sector, there was almost a complete absence of diagnostic procedures and referrals in the informal sector. We need to carefully interpret these findings as we do not have information on what drugs were prescribed by the providers. Retrospective recording of actual drugs through patient interviews is difficult and in most cases unreliable. In Bangladesh, fixed dose combination (FDC) anti-TB drugs are almost exclusively available at DOTS centres. This implies that medication provided through the informal sector is unlikely to be adequate for the management of TB. However, formal providers can manage TB cases outside the context of DOTS centres. As such, mismanagement of TB can also occur in the formal sector, given the low occurrence of diagnostic investigations.

A study in Malawi provided insight into the type of medication provided to individuals with TB symptoms but without a formal diagnosis. The authors reported that $61 \%$ of cases had been treated with antibiotics like co-trimoxazole, doxycycline and penicillin. ${ }^{25}$

NTP also recognises the absence of standard practices in the private sector and the lack of sufficient interaction and formal linkages between NTP and these private sector providers. The lessons learnt from studies aimed at establishing connections between formal and informal healthcare providers remain unexplored. ${ }^{13} 27$ Our study indicates that despite the country coverage by DOTS, and public-private-partnership activities undertaken by the NTP, the impact did not result in reducing the disconnect between NTP and the informal health sector. In a recent attempt to improve the situation, NTP in partnership with icddr,b and the US Agency for International Development (USAID) is implementing a 'Translating research into action (TRAction)' project to test different implementation strategies, with a clear role for the informal providers. This current study suggests that an attempt is timely and needed.

One of the potential limitations of the study is the potential for minor selection bias. Although all participants were randomly selected, the selection of clusters was not stratified by urban/rural setting. The study sample therefore does not fully represent $70 \%$ of the rural population in Bangladesh. There was also a slight over-representation of men. However, the national case notification is more or less static at 3:1 male to female since the inception of DOTS in $1993 .^{1}$ The strengths of the study are that the cases were interviewed at home by trained research coordinators providing an enabling study setting. We explored the care seeking of actively and passively detected cases which would cover care seeking from a wider perspective of two different kinds of cases, one who is probably in the early phase of the disease process and the other probably in a more advanced condition. Moreover, we have covered the care seeking up to the fourth point of care, which is expected 
to give a more comprehensive picture of the care seeking by the TB cases in Bangladesh.

In conclusion, it can be said that most of the initial care seeking by different types of TB cases was sought from informal providers or was limited to self-care, and that a large proportion of these cases remained in the informal sector during subsequent care seeking. It is imperative that the NTP should immediately take the initiative to engage all types of care providers, particularly the informal providers. It is also necessary to strengthen the ongoing advocacy communication and social mobilisation activities to increase awareness of key TB symptoms, availability of diagnosis and free treatment in an attempt to stimulate appropriate care seeking, and to prevent unnecessary delay in TB case management.

\author{
Author affiliations \\ ${ }^{1}$ International Centre for Diarrhoeal Disease Research, Bangladesh (icddr,b), \\ Dhaka, Bangladesh \\ ${ }^{2}$ National TB Control Programme (NTP), DGHS, Dhaka, Bangladesh \\ ${ }^{3}$ Health Programme, BRAC, Dhaka, Bangladesh \\ ${ }^{4}$ Department of Clinical Epidemiology, Academic Medical Centre, University of \\ Amsterdam, Amsterdam, The Netherlands \\ ${ }^{5}$ Centre for Infection and Immunity Amsterdam, Academic Medical Centre, \\ University of Amsterdam, Amsterdam, The Netherlands \\ ${ }^{6}$ Public Health Service, Amsterdam, The Netherlands \\ ${ }^{7}$ Department of Global Health, Academic Medical Centre, University of \\ Amsterdam, Amsterdam Institute for Global Health and Development, \\ Amsterdam, The Netherlands \\ ${ }^{8}$ KNCV Tuberculosis Foundation, The Hague, The Netherlands
}

Acknowledgements We thankfully acknowledge the National Tuberculosis Control Programme (NTP) of Bangladesh for their continuous support throughout this study. We also acknowledge the technical assistance provided by the KNCV Tuberculosis Foundation, The Netherlands. Our thanks go to all NTP partners like BRAC, Damien Foundation and others and individuals involved in this survey for their support throughout the study period. We sincerely acknowledge the contribution of our project staff and community members from all over the country, without whom this study would never have materialised.

Contributors SH was responsible for the conception and design of the study, analysis and interpretation of data and writing of the manuscript. MB, FvL and KZ participated in the conception and design of the study, analysis and interpretation of data as well as in the revision of the draft. $A Q, S B, A H$ and $A l$ participated in the analysis and interpretation of data and substantial revision of the paper.

Funding This research study was funded by WHO, the USA Agency for International Development (USAID) and Global Fund to Fight AIDS, Tuberculosis and Malaria (GFATM), grant number SEBAN TUB 001 XW06U. icddr,b acknowledges with gratitude the commitment of WHO, USAID and GFATM to its research efforts. The funders had no role in the study design, data collection and analysis, as well as in the decision to publish or preparation of the manuscript.

Competing interests None.

Ethics approval This survey protocol was approved by the institutional review board (IRB, FWA-00001468) of the International Centre for Diarrhoeal Diseases Research, Bangladesh (icddr,b). Verbal and written consent was obtained in all cases after informed appraisal.

Provenance and peer review Not commissioned; externally peer reviewed.

Data sharing statement Additional data from this survey are being analysed and will be published in future.
Open Access This is an Open Access article distributed in accordance with the Creative Commons Attribution Non Commercial (CC BY-NC 3.0) license, which permits others to distribute, remix, adapt, build upon this work noncommercially, and license their derivative works on different terms, provided the original work is properly cited and the use is non-commercial. See: http:// creativecommons.org/licenses/by-nc/3.0/

\section{REFERENCES}

1. World Health Organization. Global tuberculosis report 2013. Geneva: World Health Organization; WHO/HTM/TB/2013.11.

2. Directorate General of Health Services (DGHS). Tuberculosis in Bangladesh: annual report 2012. Dhaka: National Tuberculosis Control Programme (NTP), 2012.

3. Zafar Ullah AN, Haque R, Begum V, et al. Public private partnership for TB control in Bangladesh: role of medical practitioners in management of TB patients. World Med Health Policy 2010;2:217-34.

4. Rifat M, Rusen ID, Islam MDA, et al. Why are tuberculosis patients not treated earlier? A study of informal health practitioners in Bangladesh. Int J Tuber Lung Dis 2011;15:647-51.

5. Hossain S, Quaiyum MA, Zaman K, et al. Socio economic position in TB prevalence and access to services: results from a population prevalence survey and a facility-based survey in Bangladesh. PLoS ONE 2012;7:e44980. http://www.plosone.org/article/info:doi/10.1371/ journal.pone.0044980 (accessed 5 Aug 2013)

6. Rieder H. Case finding in tuberculosis: a comprehensive international approach. In: Reichman L, Hershfield E, eds. New York: Marcel Dekker Inc, 1993:167-82.

7. Pinto LM, Udwadia ZF. Private patients' apperceptions about a public programme; what do private Indian tuberculosis patients really feel about directly observed treatment? BMC Public Health 2010;10:1-5. http://www.biomedcentral.com/1471-2458/10/357 (accessed 5 Aug 2013).

8. Gwatkin DR, Bhuiya A, Victora CG. Making health systems more equitable. Lancet 2004;364:1273-80.

9. Yimer S, Holm-Hansen C, Yimaldu T, et al. Health care seeking among pulmonary tuberculosis suspects and patients in rural Ethiopia: a community-based study. BMC Public Health 2009;9:454. http://www.biomedcentral.com/1471-2458/9/454 (accessed 5 Aug 2013).

10. Ahmed SM, Evans TG, Standing $\mathrm{H}$, et al. Harnessing pluralism for better health in Bangladesh. Lancet 2013;382:1746-55.

11. Director General of Health Services (DGHS). National TB guidelines 2009. 4th edn. Ministry of Health and Family Welfare, Government of Bangladesh, 2009.

12. Hossain S, Larson CP, Quaiyum MA, et al. Adults with chronic cough in urban Bangladesh: healthcare utilization and management of cases by private practitioners. World Health Popul 2010;12:5-17.

13. Zafar Ullah AN, Huque $R$, Husain A, et al. Effectiveness of involving the private medical sector in the National TB Control Programme in Bangladesh: evidence from mixed methods. BMJ Open 2012;2:1-8. http://bmjopen.bmj.com/content/2/6/e001534.long (accessed 5 Aug 2013).

14. Ahmed SM, Hossain MA. Mapping of the health care providers in Bangladesh. In: James P. Grant School of Public Health, Health Workforce in Bangladesh: Who constitutes the healthcare system? The state of health in Bangladesh 2007, Bangladesh Health Watch 2007. Dhaka: BRAC University, 2008.

15. Desmet M, Bashir I, Sohel N. Illness profile and health care utilization patterns of slum residence in Dhaka city, Bangladesh. Health care seeking studies. ICDDR,B Working Paper No:111. Dhaka: International Centre for Diarrhoeal Disease Research, Bangladesh (ICDDR,B), 1998:128-32.

16. World Health Organization. Involving private practitioners in tuberculosis control: issues, interventions, and emerging policy framework. Geneva: World Health Organization, 2001, WHO/CDS/ TB/2001.285.

17. Malmborg R, Mann G, Thomson R, et al. Can public-private collaboration promote tuberculosis case detection among the poor and vulnerable? Bull World Health Organ 2006;84:752-8.

18. Zaman K, Hossain S, Banu S, et al. Prevalence of smear positive tuberculosis in persons aged $\geq 15$ years in Bangladesh: results from a national survey 2007-2009. Epidemiol Infect 2012;140:1018-27.

19. van Leth F, Guilatco RS, Hossain S, et al. Measuring socio economic data in tuberculosis prevalence surveys. Int $J$ Tuberc Lung Dis 2011;15:558-63.

20. Gwatkin DR, Rutstein S, Johnson K, et al. Country reports on HNP and poverty. Socio-economic differences in health, nutrition and population. Bangladesh: 1996/97, 1999/2000, 2004. Washington, 
DC: World Bank, Human Development Network, Health, Nutrition and Population.

21. Bangladesh Demographic and Health Survey 1999-2000. National Institute of Population, Research and Training (NIPORT). Calverton, MD: Mitra and Associates, Measure DHS+, ORC Macro, 2001.

22. Jianzhao $\mathrm{H}$, van den $\mathrm{H}$ of $\mathrm{S}$, Lin $\mathrm{X}$, et al. Risk factors for non-cure among new sputum smear positive tuberculosis patients treated in tuberculosis dispensaries in Yunnan, China. BMC Health Serv Res 2011:11:97. http://www.biomedcentral.com/1472-6963/11/97 (accessed 7 Aug 2013).

23. Ahmed SM. Exploring health-seeking behaviour of disadvantaged populations in rural Bangladesh [PhD thesis]. Stockholm, Karolinska Institutet, 2005.
24. Ahmed SM, Hossain MA, Chowdhury MR. Informal sector providers in Bangladesh: how equipped are they to provide rational health care? Health Policy Plan 2009;24:467-78

25. Salaniponi FML, Harries AD, Banda HT, et al. Care seeking behaviour and diagnostic processes in patients with smear-positive pulmonary tuberculosis in Malawi. Int J Tuber Lung Dis 2000;4:327-32.

26. Lonnroth $\mathrm{K}$, Thuong LM, Linh PD, et al. Utilization of private and public health care providers for tuberculosis symptoms in $\mathrm{Ho}$ Chi Minh city, Vietnam. Health Policy Plan 2001;16:47-54.

27. Salim HMA, Uplekar M, Daru P, et al. Turning liabilities into resources: informal village doctors and tuberculosis control in Bangladesh. Bull World Health Organ 2006;84:479-84. 